\title{
Behavioral changes in freestall-housed dairy cows with naturally occurring clinical mastitis
}

\author{
K. K. Fogsgaard, ${ }^{1}$ T. W. Bennedsgaard, and M. S. Herskin \\ Department of Animal Sciences, Aarhus University, 8830 Tjele, Denmark
}

\begin{abstract}
Dairy cows exhibit classic signs of sickness behavior during mastitis. However, knowledge about the consequences of naturally occurring mastitis in freestallhoused dairy cows, milked in automatic milking systems, is lacking. The aim of the present study was to describe the behavior of dairy cows after diagnosis and antibiotic treatment of mastitis. In the days before and after antibiotic treatment, the milking behavior, feeding, and activity were examined in 30 mastitic and 30 control Danish Holstein-Friesian cows kept in freestalls and milked by an automatic milking system. Sickness behavior was evident in the mastitic dairy cows and local clinical signs in the udder as well as behavioral changes persisted beyond the $3 \mathrm{~d}$ of antibiotic treatment. In the days before diagnosis and treatment, feed intake was reduced compared with the control animals. Although reduced by the antibiotic treatment, this difference persisted until at least $10 \mathrm{~d}$ after diagnosis. Sick cows spent less time lying in the initial days after treatment, reversing to the level of the control cows within the $10 \mathrm{~d}$ posttreatment period. In the $48 \mathrm{~h}$ before antibiotic treatment, the mastitic cows showed increased restlessness during milking, as seen by a higher frequency of tripping and kicking. Mastitic cows continued to show increased kicking during milking even after the antibiotic treatment period. These results show that the behavioral changes induced by naturally occurring mastitis persisted beyond the days of antibiotic treatment, thereby calling for further investigation into management of mastitic dairy cows to optimize recovery and ensure animal welfare during the recovery period after clinical mastitis.
\end{abstract}

Key words: dairy cow, mastitis, welfare, sickness behavior

Received May 9, 2014

Accepted November 18, 2014.

${ }^{1}$ Corresponding author: Katrine.KopFogsgaard@anis.au.dk

\section{INTRODUCTION}

It is well documented that dairy cows show signs of sickness behavior during mastitis, where changes in lying time, activity, and feeding behavior have received the most scientific attention (Siivonen et al., 2011; Fogsgaard et al., 2012; Medrano-Galarza et al., 2012). However, almost all reports on bovine sickness behavior during mastitis have studied experimentally induced mastitis, cows housed in tie stalls, and often relatively few animals (Siivonen et al., 2011; Cyples et al., 2012; Fogsgaard et al., 2012). Thus, these studies have modeled the diversity of the physiological, behavioral, and temporal responses expected to take place in naturally occurring cases, where effects of, for example, intercow competition, housing, and milking systems present in modern dairy production, must be taken into account. Only few studies have investigated changes in behavior of mastitic cows kept in freestalls (Medrano-Galarza et al., 2012; Yeiser et al., 2012), and to our knowledge, none have focused on naturally occurring mastitis in dairy cows kept in freestalls and milking by automatic milking systems (AMS), despite the increasing popularity of this housing system.

Decreased feed intake and level of activity are classical behavioral changes in response to a range of diseases in animal species, including bovine mastitis (Broom, 2006; Fogsgaard et al., 2012; Medrano-Galarza et al., 2012). In addition, reduced lying time has consistently been reported as a behavioral response in mastitic dairy cows (Siivonen et al., 2011; Cyples et al., 2012). This behavioral response, which is not part of classical sickness behavior, has been reasoned to be due to pain or soreness in the infected udder during lying. Until now, the behavior of mastitic cows during milking has not been studied, but candidates for study might be behavioral changes during mastitis due to the stimulation of the infected udder. Rousing et al. (2004) showed that dairy cows with teat lesions are more likely to kick during milking, and similar results could be expected in mastitic dairy cows when the udder is swollen and sore due to mastitis (Fitzpatrick et al., 1998; Fitzpatrick et al., 2013).

The aim of this study was to examine clinical signs of udder infection, feeding behavior, activity behavior, 
and behavior during milking in freestall-housed dairy cows in the days during and after diagnosis, and antibiotic treatment for naturally occurring mastitis by comparison with behavior of healthy control individuals kept in the same environment. We predicted that infected cows would show signs of classical sickness behavior as well as decreased lying time compared with the healthy noninfected cows. Based on the current experimental period of $10 \mathrm{~d}$, which is more than the double that of the earlier reported durations of sickness behavior after bovine mastitis, we expected that these behavioral changes would even out and normalize during the experimental period.

\section{MATERIALS AND METHODS}

\section{Housing and Animals}

Data were collected at the Danish Cattle Research Centre, Aarhus University, AU-Foulum, Denmark from October 2012 to April 2013. The resident herd consisted of 2 groups of approximately 60 cows housed in a naturally ventilated barn with concrete slatted flooring. The 2 groups were kept in adjacent mirror-image freestall pens with minimum 1 cubicle per cow (1.85 $\mathrm{m} \times 1.35 \mathrm{~m}$, length to brisket board). Both groups featured cows in different lactation number and stages. The cubicles were equipped with mattresses (Canarm/ BSM, Canarm Ltd., ON, Canada) covered by a thin layer of sawdust, which was topped automatically (JHminiStrø, JH Staldservice A/S, Holstebro, Denmark) twice a day. The cubicles were scraped manually 4 to 6 times a day. Alleys were concrete slatted floors (slats $=15 \mathrm{~cm}$, spacing $=4 \mathrm{~cm}$ ) and were scraped on a continuous basis (approximately 12 times $/ 24 \mathrm{~h}$ ) by automatic cleaning robots (Lely Discovery, Lely Holding, Maassluis, the Netherlands). Water was accessible ad libitum from a total of 4 self-filling water troughs. Each group had access to AMS (DeLaval, Tumba, Sweden) and one swinging cow brush (DeLaval). Artificial barn light was dimmed to approximately 2 to $3 \mathrm{~lx}$ between 2230 and $0500 \mathrm{~h}$, whereas inflow of natural light was allowed through the partially curtained side walls and skylights. According to the settings of the robot, cows $<150$ DIM could only be milked with a minimum interval of $5 \mathrm{~h}$ or $7 \mathrm{~kg}$ of milk per milking, whereas cows $>150$ DIM were allowed to be milked with an interval of minimum $8 \mathrm{~h}$ or $8 \mathrm{~kg}$ of milk per milking. The AMS software (DeLaval) calculated the milking interval of individual cows based on information from previous milkings and DIM. Irrespective of the DIM, cows with a milking interval exceeding $15 \mathrm{~h}$ were fetched for milking by barn staff twice a day at approximately 0500 and
$1430 \mathrm{~h}$ and milked in the AMS. For all cows, access to the AMS was denied for approximately $45 \mathrm{~min}$ daily due to automatic cleaning at 0400 and $1900 \mathrm{~h}$.

Fresh feed was provided daily at $0700 \mathrm{~h}$ and topped up 3 times between 1100 and $2100 \mathrm{~h}$. The cows were fed from computer-operated feeding bins (Insentec B.V, Marknesse, the Netherlands, maximum 2.5 cows/ bin), and all cows were fed a total mixed ration for ad libitum intake. However, due to concurrent nutritional experiments, some minor feed components varied between rations. In addition, each cow was allowed $3 \mathrm{~kg}$ of concentrate daily in the AMS.

\section{Inclusion Criteria and Clinical Mastitis Diagnosis}

The herd was screened daily during milking, as part of normal procedure, for cases of mastitis. In case of suspected mastitis infection, due to elevated lactate dehydrogenase (measured by Herd Navigator, Lattec I/S, Hillerød, Denmark), SCC (measured by online cell counter, DeLaval), or conductivity levels (measured by the AMS system) compared with individual cow baselines, a California Mastitis Test (CMT; DeLaval) was conducted. The CMT scores ranged from $1(<200,000$ somatic cells) to $5(>5,000,000$ somatic cells). In cases of CMT $\geq 4$, milk samples from the affected quarter(s) were aseptically collected and shipped for bacteriological culture. Test results were received within $24 \mathrm{~h}$. Culturing was performed according to the Laboratory Handbook on Bovine Mastitis (National Mastitis Council, 1999). Samples with 2 or more colonies of the same species were considered positive $(\geq 200 \mathrm{cfu} / \mathrm{mL})$.

During the preset experimental period of $6 \mathrm{mo}$, a total of 30 mastitic cows were included in the study. All the cows were diagnosed with naturally occurring clinical mastitis, based on the presence of bacteria in the milk, and could not be included if they had any other clinically evident disease during the last $30 \mathrm{~d}$. Within $24 \mathrm{~h}$ after the initial collection of milk samples, infected cows were treated for $3 \mathrm{~d}$ with antibiotics. The initial day of treatment was defined as $\mathrm{d} 0$. The applied active pharmaceutical ingredients depended on type of pathogen; penicillin-sensitive pathogens were treated systemically and locally with narrow spectrum penicillin; penicillin-resistant pathogens were treated systemically by injection with amoxicillin and locally with cloxacillin/ampicillin. Local and systemic antibiotic treatment was given at $\mathrm{d} 0$, whereas treatments on $\mathrm{d} 1$ and 2 were systemic. Normal farm treatment routine and procedure were followed during this experiment where we prioritized the involvement of daily onfarm procedures. All mastitic cows were treated with antibiotics between 0700 and 1000 h. No analgesics were administered. 
Each infected cow was paired with a clinically healthy control cow from the same home pen matched by lactation stage, DIM, yield (L/d), lameness score, $\mathrm{BCS}$, and type of feed according to a matched-pair design (Ersboll et al., 2004). Furthermore, only cows with SCC $<100,000$ cells/mL at the day of selection [based on the online cell counter (DeLaval)] and no medical treatment record within the last $30 \mathrm{~d}$ could be included as controls. For control and mastitic animals, cows with a lameness score $>3$ (Thomsen et al., 2008) were excluded.

\section{Experimental Design}

Throughout the experimental period, the type, as well as magnitude, of human handling were standardized as much as possible between controls and infected cows. Pairs of mastitic and control cows were chosen from the same home pen and kept there during the observation period. To ensure standardization of the level of human handling, both cows within an experimental pair were separated from the group and kept in headlocks for 15 to $30 \mathrm{~min}$, when the mastitic cows were treated with antibiotics. During this period, activity sensors (IceTag or IceQube, IceRobotics Ltd., Edinburgh, UK) were placed on one hind leg of each cow. All individuals were marked with different colored collars, enabling identification from video recordings. During the $10 \mathrm{~d}$ experimental period from d 0 and onward, all cows included in the study were kept in the herd and were part of normal management routines.

\section{Data Collection and Variables}

The experimental data are based on automatic registrations of feeding behavior, activity data from the automated recording devices, analyses of behavior during milking, as well as clinical exams.

Feeding Behavior and Feed Intake. Feed intake $(\mathrm{kg} / \mathrm{d})$, number of visits to the feed bins, and time spent feeding were recorded automatically by the feed bins from $\mathrm{d}-10$ to +10 . Feeding rate was calculated as feed intake per time unit spent feeding $(\mathrm{kg} / \mathrm{min})$. Three feeding bouts from one individual cow had to be excluded due to technical issues with a feed bin. No feed data from precalving were included.

Activity Data. Measures of cow activity were downloaded from the IceTags to the IceManager2010 software (IceRobotics Ltd., Scotland, UK). The total lying time, number of lying bouts, and the number of steps taken per day were recorded for each cow from $\mathrm{d} 0$ to 10. A cow could only be classified as lying, if she had been lying for more than $1 \mathrm{~min}$, and a new lying bout could only be initiated after intervals of at least $1 \mathrm{~min}$.

Behavior During Milking. During each milking from $\mathrm{d}-2$ to 10 , the behavior of the cows was recorded by a video camera positioned on the wall facing toward the AMS (distance approximately $2 \mathrm{~m}$ ) and allowing a free view of the hind part of the cow during milking. Data were obtained using MSH Video Client (version 5.0.11.136, M. Shafro \& Co, Riga, Latvia). Dairy cow behavior was analyzed by 2 trained observers, ensuring that the behavior of each matched pair was always observed by the same person. The observers were blind to the disease status of the cows. If the view was blocked or the cow had to be calmed by handlers during milking, this period was excluded. Table 1 shows an ethogram of the recorded behavioral patterns. Milking sessions where the cow had been out of sight, or calmed to such an extent that less than 1.5 min of the milking remained for behavioral recordings, were excluded. The duration of all milkings was registered.

Clinical Examinations and Milk Analyses. At time of antibiotic treatment, all experimental cows went through a thorough clinical examination, including palpation of the udder, measurement of rectal temperature, and CMT. This was conducted to rule out acute cases of mastitis in the control cows and other signs of disease in the experimental animals. Table 2 shows the scores used for the clinical udder examination. The presence of quarter hardness, redness, swelling, milk drip, and soreness was scored (0/1). During the following $10 \mathrm{~d}$, the clinical examination was repeated each morning between 0700 and $1000 \mathrm{~h}$. This examination took place in a cubicle in the home environment and was performed by trained technicians. The technicians could not be blinded to treatment groups as cows treated with antibiotics must be clearly marked for identification by the barn staff.

Table 1. Ethogram of behavior of dairy cows during milking in an automatic milking unit ${ }^{1}$

\begin{tabular}{|c|c|c|}
\hline Behavior & Definition & Measurement \\
\hline Duration & The interval from the cow enters the AMS and the gate closes until the front gate opens & Time (mm:ss) \\
\hline Trip & One hoof is lifted less than $15 \mathrm{~cm}$ off the ground (Rushen et al., 2001) & Frequency/min \\
\hline Kick & Kick in any direction, 1 hoof is lifted at least $15 \mathrm{~cm}$ off the ground (Rushen et al., 2001) & Frequency $/ \mathrm{min}$ \\
\hline Out of sight & Camera view is blocked & Time (mm:ss) \\
\hline Cow calmed & Cow is calmed by person, which can be seen on the recording & Time (mm:ss) \\
\hline
\end{tabular}

${ }^{1}$ Data were recorded from $2 \mathrm{~d}$ prior $(\mathrm{d}-2)$ to antibiotic treatment for clinical mastitis until $10 \mathrm{~d}$ after initiation of treatment $(\mathrm{d} 0)$. 
Table 2. Scores obtained during the clinical udder examination performed daily from d 0 to 10 after antibiotic treatment for clinical mastitis in dairy cows ${ }^{1}$

\begin{tabular}{|c|c|c|c|}
\hline Variable & Criteria/scale & Score & Guideline \\
\hline Quarter firmness & Firm & 1 & $\begin{array}{l}\text { Fingers palpate maximum } 3 \text { to } 5 \mathrm{~cm} \\
\text { into the tissue }\end{array}$ \\
\hline Quarter swelling & Minimum 1.5 times & 1 & \\
\hline Quarter redness & None & 0 & One or more quarters are reddened \\
\hline Milk secretion & Milk & 1 & \\
\hline \multirow[t]{2}{*}{ Sign of possible soreness } & None & 0 & $\begin{array}{l}\text { Disruptive/pull away at first touch } \\
\text { at the udder }\end{array}$ \\
\hline & Present & 1 & \\
\hline \multirow{2}{*}{$\begin{array}{l}\text { Included in examination on d } 0 \text { to rule out other diseases } \\
\text { Hydration rate }\end{array}$} & & & \\
\hline & $\begin{array}{l}\text { None } \\
\text { Moderate }\end{array}$ & $\begin{array}{l}0 \\
1\end{array}$ & Degree of enophthalmos \\
\hline
\end{tabular}

${ }^{1}$ Scoring system modified from Wenz et al. (2006).

\section{Statistical Analysis}

Data from a total of 60 cows were collected [30 control (DIM: $85 \pm 72$; mean \pm SD) +30 mastitic (DIM: $69 \pm 75$; mean $\pm \mathrm{SD})]$. Of the 30 mastitic cows, 9 were primiparous and 21 were multiparous, and the controls were matched. However, due to technical difficulties, the activity data included only 44 individuals (20 mastitic +24 controls). The bacteriological analyses revealed that 6 different bacterial species were involved and that Staphylococcus aureus and Streptococcus uberis accounted for more than half of the cases.

Based on initial visual inspection as well as statistical analysis of the data split into 24 -h periods (results not shown), the data were categorized into longer periods (each lasting 3 to $4 \mathrm{~d}$ ) to enhance the power of the statistical models by reducing the degrees of freedom involved. A period duration of at least $3 \mathrm{~d}$ was chosen based on the 3-d period of antibiotic treatment. Consequently, activity data and clinical registrations were analyzed as 3 periods (d 0 to 2,3 to 5 , and 6 to 10), and similarly for the behavior during milking, where a fourth period ( $\mathrm{d}-2$ to -1 ) was included. Feeding data were analyzed as 6 periods ( $\mathrm{d}-10$ to $-7,-6$ to $-4,-3$ to $-1,0$ to 2,3 to 5 , and 6 to 10 ). All statistical analyses were performed with SAS Enterprise Guide software (version 5.1, SAS Institute Inc., Cary, NC). Degrees of freedom were calculated using Satterthwaite's approximation. If nothing else is mentioned, results are given as least squares means \pm standard error as well as $F\left(\mathrm{df}_{\text {treatment }}, \mathrm{df}_{\text {error }}\right)$ and the corresponding $P$-values. Data were considered significant when $P<0.05$ and as a tendency when $0.05 \leq P<0.1$.
Behavioral Data. The duration of milking and the frequency of hind leg lifts and kicks during milking were analyzed by a general linear model (GLM, PROC GENMOD) including the identity of the individual cow as a repeated measure. Milking duration was modeled as a normal distribution, whereas a negative binominal distribution was used to model the frequency of lifts and kicks. Feed intake, number of feeding bouts, feeding rate, number of steps, number of lying bouts, as well as the lying time were calculated per cow and day and analyzed as continuous dependent variables in a mixed model (PROC MIXED) including the identity of the individual cow as a repeated measure. Across periods, within-animal measures were assumed correlated, leading to the use of a compound symmetric or a first-order autoregressive covariance structure, the choice of which was based on the best fit assessed using the Akaike's information criterion (lowest values preferred; SAS Institute Inc., Cary, NC). For all analysis bacterial species, disease status (mastitic/control), lactation number (1-6), period (1-6), and the interaction between period and disease status were included as fixed effects. For individual cows, the choice of antibiotic drug and dosage depended on the bacterial species present in the udder, which is why drug type was not included as an individual fixed effect. However, neither bacterial species nor lactation number explained variation in the clinical score or the behavioral measures and hence were excluded from all the final models.

Clinical Data. The presence of clinical signs (0/1) was turned into a daily clinical score for each individual ranging from 0 to 5 , by summation of all scores per cow and day. Hydration rate and rumen contraction rate 
was only examined on d 0 , to rule out other diseases, and thus not included in the statistical analysis. The effect of disease status on the clinical score was analyzed with a GLM (PROC GENMOD) including a negative binominal distribution and the repeated-measures statement. Fixed effects as well as the choice of covariance structure were similar to the behavioral variables.

\section{RESULTS}

\section{Behavioral Data}

For most behavioral variables, significant differences between mastitic and control cows were found. Infected cows had a lower feed intake $(41.0 \pm 1.7$ vs. $43.5 \pm 1.7$ $\left.\mathrm{kg} / \mathrm{d} ; F_{3,1100}=36.51, P<0.001\right)$, feeding rate $(0.22$ \pm 0.003 vs. $0.26 \pm 0.003 \mathrm{~kg} / \mathrm{min} ; F_{1,1129}=8.46, P=$ $0.004)$, and lying time $(732 \pm 20$ vs. $756 \pm 20 \mathrm{~min} / \mathrm{d}$; $\left.F_{1,365}=5.76, P=0.017\right)$ across the entire observation period. Within this period, mastitic cows showed an increased frequency of lifting their hind legs $(2.8 \pm 0.09$ vs. $2.6 \pm 0.07$ lifts/milking; $\left.\chi^{2}=17.62, P<0.001\right)$ and kicking $(1.7 \pm 0.5$ vs. $0.00 \pm 0.001$ kicks/milking; $\left.\chi^{2}=7.12, P<0.001\right)$ during milking in the AMS. Mastitic cows also took more steps $(1,380 \pm 58$ vs. $1,284 \pm 56$ steps $\left./ \mathrm{d} ; F_{1,375}=4.79, P=0.029\right)$ and had a higher number of daily lying bouts $(2.4 \pm 0.05$ vs. $2.2 \pm$ 0.05 bouts $\left./ \mathrm{d} ; F_{1,375}=24.35, P<0.001\right)$ compared with healthy controls during the entire observation period.

Effects of period were found for feed intake, showing that the feed intake was lower before antibiotic treat- ment (d 0 to 3 ) and increased with time for both control and mastitic cows $\left(F_{3,1100}=16.12, P<0.001\right.$, Figure 1$)$. The temporal development in activity, behavior during milking, and feed intake is shown in Figures 1, 2, and 3. Number of feeding bouts and milking time did not differ between mastitic cows and controls or across periods $(P>0.05)$. No significant interactions were found between period and disease status for any of the behavioral variables.

\section{Clinical Data}

Four mastitic cows had rectal temperatures above $39^{\circ} \mathrm{C}$ on d 0 , after which no cases of fever was detected during the 10-d period. Udder score varied from 0 to 4. For the mastitic cows, udder score declined over time $\left(\chi^{2}=10.33, P<0.006\right)$ but remained higher than for the control group during the whole 10-d observation period $\left(\chi^{2}=59.31, P<0.001\right.$, Figure 4$)$. Hence, on $\mathrm{d}$ 10 , the mastitic cows still had a higher udder score $[P$ $=0.011,1.3$ vs. $0.7,95 \% \mathrm{CI}(0.9,1.6)$ and $(0.4,0.9)$, respectively] than the control animals.

\section{DISCUSSION}

The results of the present study show that sickness behavior was evident in dairy cows with naturally occurring mastitis milked in an automatic milking system. In addition to the formerly described changes in feeding, activity level, and lying behavior, we found increased stepping and kicking during milking, sup-

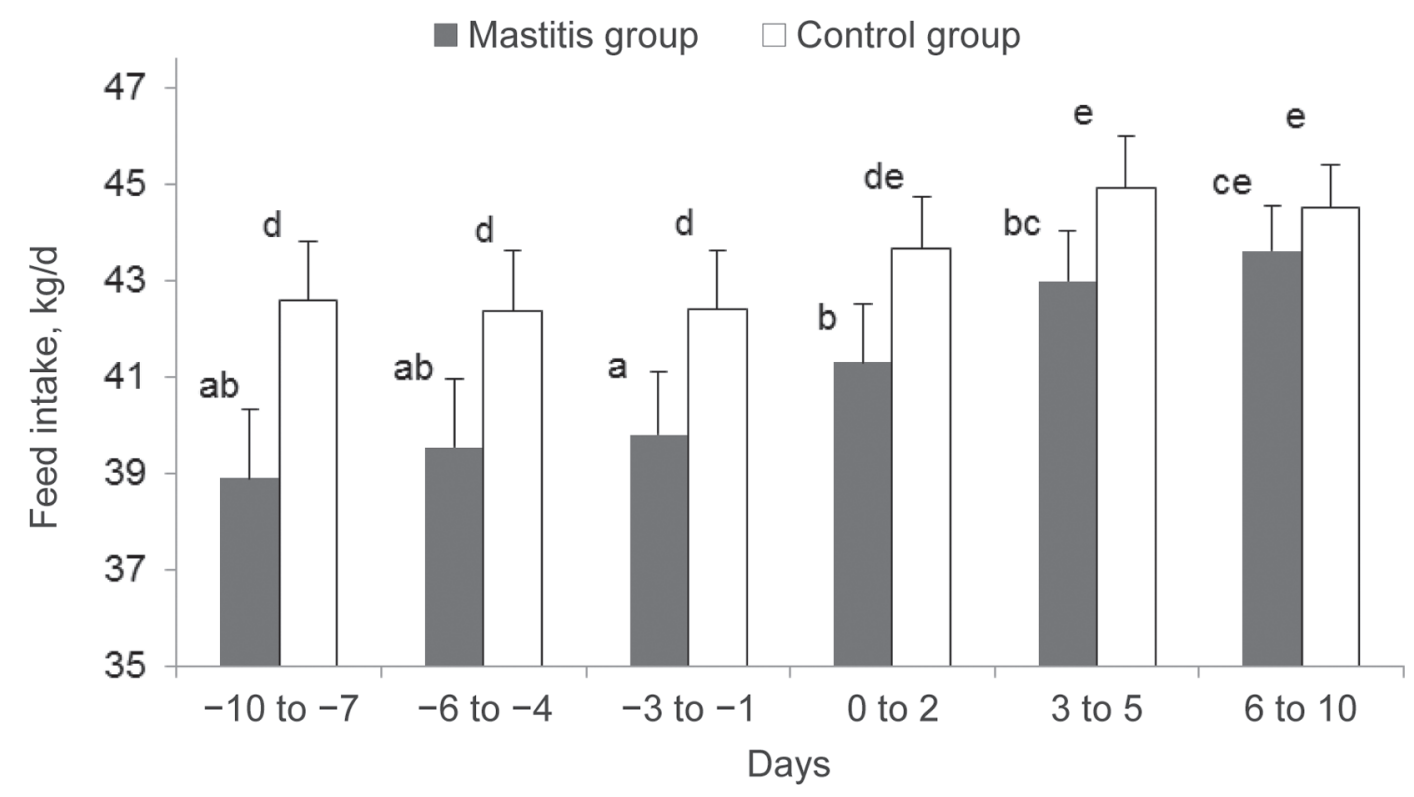

Figure 1. Daily feed intake in mastitic and healthy dairy cows fed ad libitum. Mastitic cows were treated with antibiotics on d 0,1 , and 2. Across the whole period, a difference between mastitic cows and controls was found $(P<0.05)$. Data are presented as means and standard errors. Bars with different letters (a-e) differ significantly $(P<0.05)$. 
Mastitis group

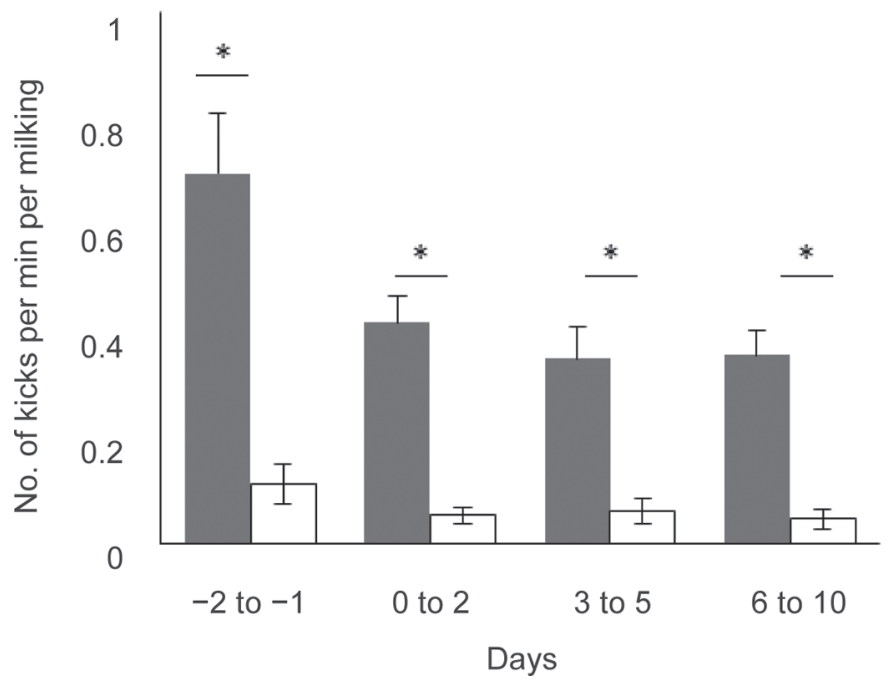

Control group

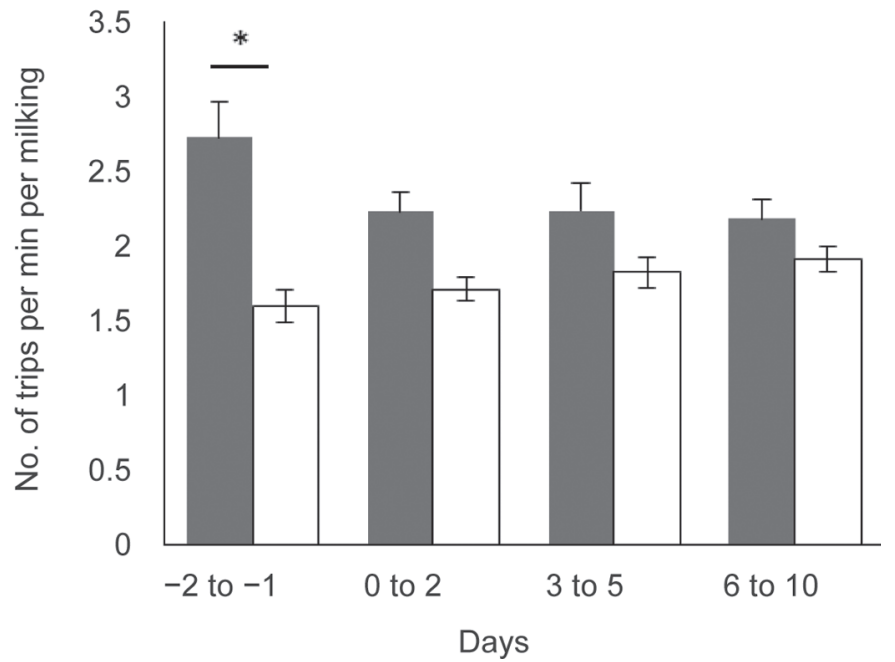

Figure 2. Average frequency of tripping and kicking per minute per milking in an automatic milking unit for mastitic dairy cows and healthy controls. Mastitic cows were treated with antibiotics on d 0,1 , and 2. Data are presented as means and standard errors. $*$ An asterisk indicates significant difference between control and mastitis group $(P<0.05)$.

porting the suggestion that mastitic dairy cows experience pain from the udder. Unexpectedly, local clinical udder signs as well as behavioral changes persisted throughout the 10-d observation period, constituting $1 \mathrm{wk}$ after antibiotic treatment. These results call for further investigation into management of mastitic dairy cows to optimize recovery and ensure animal welfare during the period after clinical mastitis.

In the present study, the mastitic cows had a higher clinical score than control animals, and although the difference in the score decreased with days after treatment, a higher clinical score persisted throughout the 10-d observation period. No animals showed systemic responses, such as fever, beyond d 0, which is why no cases of severe clinical mastitis were included (Wenz et al., 2006). Recent descriptions of altered behavior during experimentally induced clinical bovine mastitis have shown normalization within a few days after diagnosis (Siivonen et al., 2011; Fogsgaard et al., 2012). With this in mind, it is striking that the present naturally occurring mastitis cases led to several behavioral changes and local clinical signs, persisting for at least $10 \mathrm{~d}$ after initiation of treatment.

None of the cows received analgesics or nonsteroidal anti-inflammatory drugs (NSAID), and it cannot be ruled out that administration of these could have affected the present findings. Changes in behavior as well as clinical signs of mastitis have been shown to be

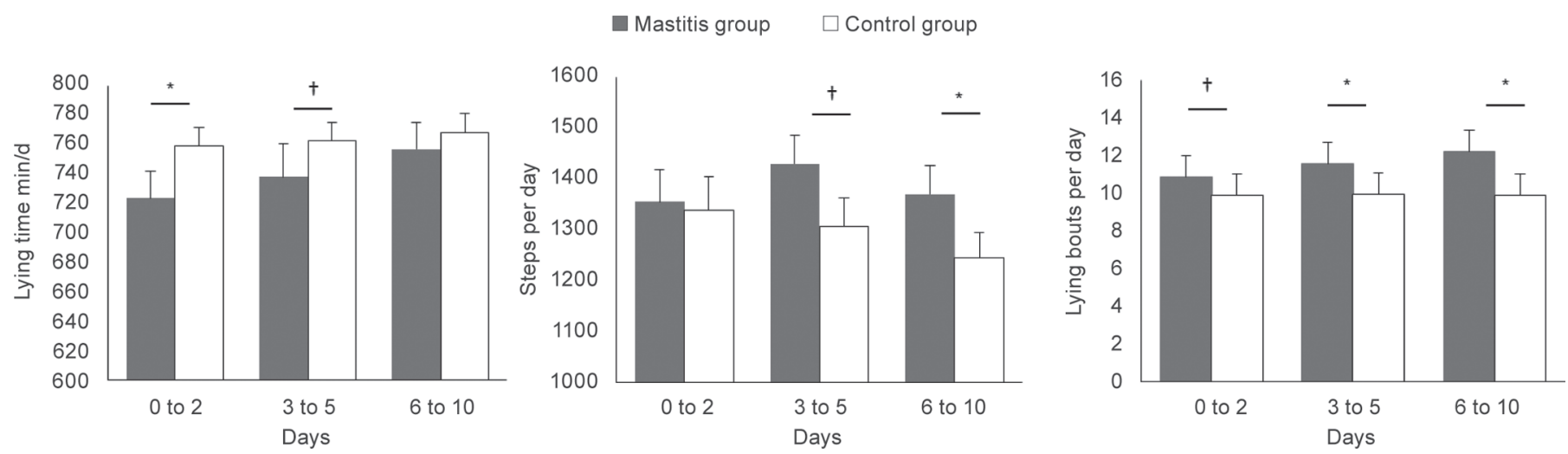

Figure 3. Daily lying time, steps, and lying bouts of freestall-housed dairy cows. Mastitic cows were treated with antibiotics on d 0, 1, and 2. Data are presented as estimated means and standard errors. ${ }^{*}$ An asterisk indicates a significant difference between control and mastitis group $(P<0.05) ; \dagger$ (dagger) marks a strong tendency $(P<0.1)$. 


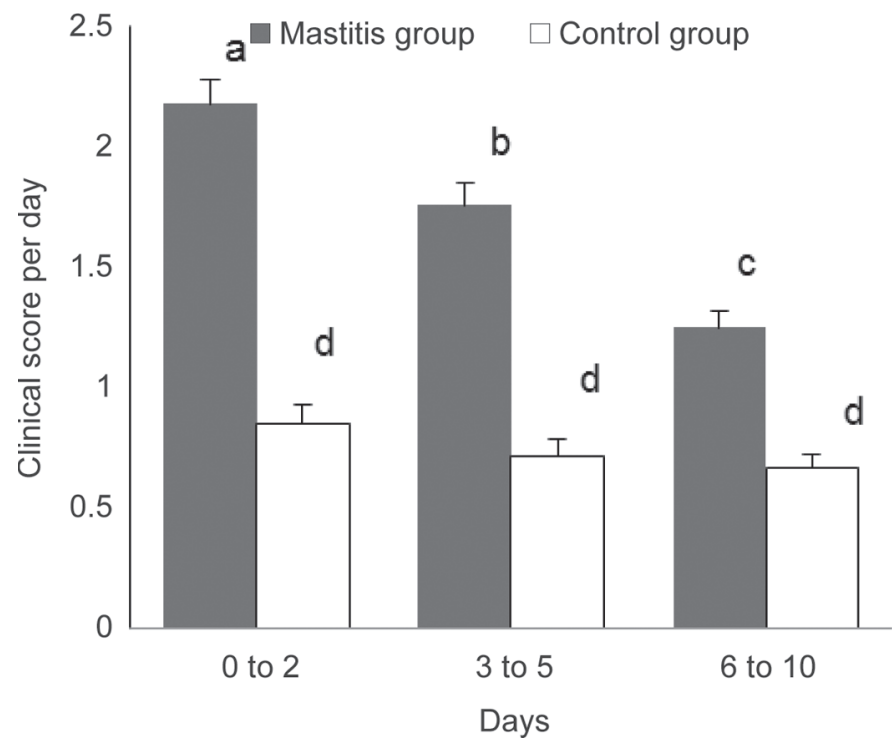

Figure 4. Clinical score is based on the sum of the score $(0 / 1)$ of quarter hardness, redness, swelling, milk drip, and soreness in the udder. Mastitic cows were treated with antibiotics on d 0,1, and 2. Data are presented as means and standard errors. Bars with different letters (a-d) differ significantly $(P<0.05)$.

reduced when NSAIDs are used as supportive therapy during the acute stage of clinical mastitis (McDougall et al., 2009; Yeiser et al., 2012; Fitzpatrick et al., 2013). However, the effect of NSAID on for instance recovery time in relation to milking behavior is unknown. Thus, further research is needed, focusing on the recovery period of mastitic dairy cows to improve recovery and ensure cow welfare during the period after the diagnosis.

The results of the present study support earlier findings of changes in activity and add new knowledge to the temporal extent of the effects in naturally occurring cases, lasting for at least $10 \mathrm{~d}$ after mastitis diagnosis. Across animal species, lying is often increased during illness (Johnson, 2002; Broom, 2006), where the reduced activity is considered beneficial for energy conservation and maintenance of the febrile response (Johnson, 2002). However, the present finding, that also free-stall-housed, naturally infected dairy cows have reduced lying time, supports results from earlier studies with different housing systems (Siivonen et al., 2011; Yeiser et al., 2012). Hence, across typical housing systems and in experimentally induced as well as naturally occurring mastitis cases of acute clinically mastitis, decreased lying behavior may be considered a response to the udder infection.

Lying behavior is highly prioritized in cattle (Jensen et al., 2004). Based on the use of operant conditioning techniques, heifers have an inelastic demand for lying of 12 to $13 \mathrm{~h} / \mathrm{d}$ (Jensen et al., 2005). Previous studies of mastitic cows in a stanchion barn (Siivonen et al.,
2011) showed that sick cows lay down approximately $11 \mathrm{~h}$ per $\mathrm{d}$ after experimentally induced mastitis. In the present study, lying time showed a gradual increase from approximately 12 to $12.5 \mathrm{~h}$ over the $10 \mathrm{~d}$, whereas the healthy cows had a stable lying time of $12.5 \mathrm{~h}$ during the entire registration period. Hence, the present lying time of the sick cows was not markedly reduced compared with findings from studies of behavioral needs of dairy cows (Jensen et al., 2004, 2005). However, the observed reduction in lying time contradicts expectations for sick animals, which would be expected to increase lying time (Broom, 2006; Dantzer and Kelly, 2007), suggesting that the reduced lying time may be important from a welfare point of view. As discussed by Siivonen et al. (2011) and Fogsgaard et al. (2012), a possible explanation for the reduced lying time is pain or soreness from the udder. This may be supported by the present results because the local clinical signs of mastitis, such as swelling and redness of the udder, also persisted during the 10-d observation period. In case of clinical signs of udder infection, lying behavior might be aversive and consequently be reduced in spite of an expected illness-induced motivation for lying (Dantzer and Kelly, 2007). Thwarting of highly motivated behavior, such as lying in cattle, causes frustration (Dawkins, 1988; Broom, 1991), and this negative state might exacerbate suffering of ill individuals. If lying is painful for the cow (Fitzpatrick et al., 1998; Leslie et al., 2010) and thus reduced, the cow might become increasingly frustrated and restless with time. The present number of steps taken and frequency of lying bouts may be indicative of such motivational conflict and hence of coping difficulties in response to the disease. If this is correct, cows with coping difficulties might benefit from changing the daily routines. However, more knowledge about preferences and needs of mastitic cows, and sick cows in general, as well as knowledge about relations between level of clinical signs and the behavioral responses within individual cows, are needed to enhance animal welfare during sickness.

Changes in behavior during milking have been linked to the clinical condition of the udder (Rousing et al., 2004) and suggested to be induced by pain or other unpleasant experiences (Grandin, 1997; Chapinal et al., 2010). If pain is present during clinical mastitis (as suggested by Fitzpatrick et al., 1998; Leslie et al., 2010), milking might be a stressful and painful experience. Hence, the present findings of increased kicking in the mastitic cows during the entire observation period might further indicate the presence of pain from the infected udder, at least as soreness, when the udder is stimulated at milking. This would be consistent with Medrano-Galarza et al. (2012) showing a higher frequency of kicking and leg lifting during milking in the 
first $3 \mathrm{~d}$ after diagnosis of clinical mastitis and Gygax et al. (2008) showing increased leg lifting in cows with high SCC, although not diagnosed with mastitis.

In the present study, we had access to data on feeding from a 20 -d period from $d-10$ to 10 . Compared with the healthy controls, feed intake of the mastitic cows was lower in the $10 \mathrm{~d}$ before diagnosis. Later, the intake was gradually increasing but remained lower than the control cows during the entire observation period. The present data set included several cows in early lactation stages, where feed intake is low and increasing (Huzzey et al., 2007). However, because the experimental pairs were carefully matched according to lactation stage, effects of the naturally occurring increase in feed intake after calving can be ruled out.

Feeding pattern and intake have been suggested indicators of disease in dairy cows (González et al., 2008); however, so far the results have been diverse. Vels et al. (2009) and Fogsgaard et al. (2012) showed an initial decrease in feed intake and a return to normal levels within $48 \mathrm{~h}$ in cows experimentally infected with LPS/ Escherichia coli, and Bareille et al. (2003) showed decreased feed intake in dairy cows with naturally occurring local as well as systemic mastitis. Other reports, using similar or higher doses of E. coli, were not able to show effects of the mammary infection on feed intake (Barrett et al., 1997). However, the present results suggest that the intake might be an early indicator of mastitis because it decreased by 7 to $10 \%$ for more than $4 \mathrm{~d}$ before mastitis diagnosis and treatment. Similar results have been reported in cows suffering from other diseases such as ketosis or metritis (Bareille et al., 2003). Whether the feed intake is reduced due to the developing infection, or the decreased feed intake precedes the infection and thereby leads to an increased risk of infection, is unknown. Further studies are important to understand this as well as potentially prevent diseases.

The present decrease in feed intake persisted after antibiotic treatment, so feeding behavior may be a potential indicator of recovery status after the period of antibiotic treatment. So far, focus has been on behavior as a tool for disease detection. This is, to our knowledge, the first time a behavior has been suggested as a recovery indicator. If this is the case, it might be possible to use automatic surveillance of recovery status, because feeding is relatively easy to monitor compared with other types of sickness behavior, such as behavior during milking. To gain more knowledge about possible recovery indicators, including feed intake, studies of correlations between behavior and clinical signs of disease within individual cows are needed. Furthermore, time series data are needed to rule out effects of, for instance, DIM. Taken together, the present results confirm that changes in feeding behavior can be used for disease detection in dairy cows and suggest that changes in this behavioral measure may serve as an indicator of recovery as well.

\section{CONCLUSIONS}

The results of the present study show that sickness behavior was evident in dairy cows with naturally occurring mastitis of rather low severity. In addition to the formerly described changes in feeding and activity level, the present findings suggest that mastitis, even without systemic clinical signs, is an aversive experience, because the cows were more restless during milking and had a lowered lying time contrary to what is normally seen in sick animals. Unexpectedly, local clinical udder signs as well as behavioral changes persisted throughout the 10-d observation period, constituting 1 wk after antibiotic treatment. These results call for further investigation into management and recovery of mastitic dairy cows to ensure animal welfare during the period after clinical mastitis as well as to optimize recovery.

\section{ACKNOWLEDGMENTS}

The authors gratefully acknowledge the help from the entire staff at the Danish Cattle Research Centre, Aarhus University, Denmark. In particular, we thank Knud A. Primdal and Bjarne Sørensen for their help with the data collection. Very special thanks go to Carsten K. Christensen (Department of Animal Science, Aarhus University, Denmark) for his work with collecting data and installing videos. Thanks to Betty Skou and Rachel AKL for doing the behavioral registrations from the video. A special thanks to Katy Proudfoot (College of Veterinary Medicine, The Ohio State University) for her helpful comments concerning the manuscript. Thanks to Martin Bjerring, Birthe Houbak, Connie H. Middelhede, Erik Luc Decker, and Lars B. Gildbjerg (Department of Animal Science, Aarhus University, Denmark) for information technology support and statistical help. The experimental part of the project was funded by the Danish Center for Animal Welfare. The project was conducted as part of a $\mathrm{PhD}$ partly funded by the BIOSENS project, granted by the Danish Ministry of Food, Agriculture and Fisheries Copenhagen, Denmark (Innovations Law), Lattec A/S (Hillerod, Denmark), and the Danish Cattle Association (Aarhus, Denmark).

\section{REFERENCES}

Bareille, N., F. Beaudeau, S. Billon, A. Robert, and P. Faverdin. 2003. Effects of health disorders on feed intake and milk production in dairy cows. Livest. Prod. Sci. 83:53-62.

Barrett, J. J., J. S. Hogan, W. P. Weiss, K. L. Smith, and L. M. Sordillo. 1997. Concentrations of [alpha]-tocopherol after intramam- 
mary infusion of Escherichia coli or lipopolysaccharide. J. Dairy Sci. 80:2826-2832.

Broom, D. M. 1991. Animal welfare: Concepts and measurement. J. Anim. Sci. 69:4167-4175.

Broom, D. M. 2006. Behaviour and welfare in relation to pathology. Appl. Anim. Behav. Sci. 97:73-83.

Chapinal, N., A. M. de Passille, J. Rushen, and S. Wagner. 2010. Automated methods for detecting lameness and measuring analgesia in dairy cattle. J. Dairy Sci. 93:2007-2013.

Cyples, J. A., C. E. Fitzpatrick, K. E. Leslie, T. J. DeVries, D. B. Haley, and N. Chapinal. 2012. Short communication: The effects of experimentally induced Escherichia coli clinical mastitis on lying behavior of dairy cows. J. Dairy Sci. 95:2571-2575.

Dantzer, R., and K. W. Kelly. 2007. Twenty years of research on cytokine-induced sickness behavior. Brain Behav. Immun. 21:153-160.

Dawkins, M. S. 1988. Behavioral deprivation - A central problem in animal-welfare. Appl. Anim. Behav. Sci. 20:209-225.

Ersboll, A. K., N. Toft, and J. Bruun. 2004. Observational studies, Pages 47-60 in Introduction to Veterinary Epidemiology. H. Houe, A. K. Ersboll, and N. Toft, ed. Biofolia, Frederiksberg C, Denmark.

Fitzpatrick, C. E., N. Chapinal, C. S. Petersson-Wolfe, T. J. DeVries, D. F. Kelton, T. F. Duffield, and K. E. Leslie. 2013. The effect of meloxicam on pain sensitivity, rumination time, and clinical signs in dairy cows with endotoxin-induced clinical mastitis. J. Dairy Sci. 96:2847-2856. (Abstr.)

Fitzpatrick, J. L., F. J. Young, D. Eckersall, D. N. Louge, C. J. Knight, and A. Nolan. 1998. Recognising and controlling pain and inflammation in mastitis. Pages 36-44 in Vol. Axient/Institute for Animal Health, Milk Development Council/Novartis Animal Health.

Fogsgaard, K. K., C. M. Rontved, P. Sorensen, and M. S. Herskin. 2012. Sickness behavior in dairy cows during Escherichia coli mastitis. J. Dairy Sci. 95:630-638.

González, L. A., B. J. Tolkamp, M. P. Coffey, A. Ferret, and I. Kyriazakis. 2008. Changes in feeding behavior as possible indicators for the automatic monitoring of health disorders in dairy cows. J. Dairy Sci. 91:1017-1028.

Grandin, T. 1997. Assessment of stress during handling and transport. J. Anim. Sci. 75:249-257.

Gygax, L., I. Neuffer, C. Kaufmann, R. Hauser, and B. Wechsler. 2008. Restlessness behaviour, heart rate and heart-rate variability of dairy cows milked in two types of automatic milking systems and auto-tandem milking parlours. Appl. Anim. Behav. Sci. 109:167-179.

Huzzey, J. M., D. M. Veira, D. M. Weary, and M. A. G. von Keyserlingk. 2007. Prepartum behavior and dry matter intake identify dairy cows at risk for metritis. J. Dairy Sci. 90:3220-3233.

Jensen, M. B., L. Munksgaard, L. J. Pedersen, J. Ladewig, and L. Matthews. 2004. Prior deprivation and reward duration affect the demand function for rest in dairy heifers. Appl. Anim. Behav Sci. 88:1-11.

Jensen, M. B., L. J. Pedersen, and L. Munksgaard. 2005. The effect of reward duration on demand functions for rest in dairy heifers and lying requirements as measured by demand functions. Appl. Anim. Behav. Sci. 90:207-217.

Johnson, R. W. 2002. The concept of sickness behavior: A brief chronological account of four key discoveries. Vet. Immunol. Immunopathol. 87:443-450.

Leslie, K. E., C. Kielland, and S. Millman. 2010. Is mastitis painful and is therapy for pain beneficial? Pages 114-130 in Proc. National Mastitis Council, Albuquerque, NM. National Mastitis Counc., Madison, WI.

McDougall, S., M. A. Bryan, and R. M. Tiddy. 2009. Effect of treatment with the nonsteroidal antiinflammatory meloxicam on milk production, somatic cell count, probability of re-treatment, and culling of dairy cows with mild clinical mastitis. J. Dairy Sci. 92:4421-4431.

Medrano-Galarza, C., J. Gibbons, S. Wagner, A. M. de Passille, and J. Rushen. 2012. Behavioral changes in dairy cows with mastitis. J. Dairy Sci. 95:6994-7002.

National Mastitis Council. 1999. Laboratory Handbook on Bovine Mastitis. Rev. ed. National Mastitis Council Inc., Madison, WI.

Rousing, T., M. Bonde, J. H. Badsberg, and J. T. Sorensen. 2004 Stepping and kicking behaviour during milking in relation to response in human-animal interaction test and clinical health in loose housed dairy cows. Livest. Prod. Sci. 88:1-8.

Rushen, J., L. Munksgaard, P. G. Marnet, and A. M. DePassille. 2001. Human contact and the effects of acute stress on cows at milking. Appl. Anim. Behav. Sci. 73:1-14.

Siivonen, J., S. Taponen, M. Hovinen, M. Pastell, B. J. Lensink, S Pyorala, and L. Hanninen. 2011. Impact of acute clinical mastitis on cow behaviour. Appl. Anim. Behav. Sci. 132:101-106.

Thomsen, P. T., L. Munksgaard, and F. A. Togersen. 2008. Evaluation of a lameness scoring system for dairy cows. J. Dairy Sci 91:119-126.

Vels, L., C. M. Rontved, M. Bjerring, and K. L. Ingvartsen. 2009. Cytokine and acute phase protein gene expression in repeated liver biopsies of dairy cows with a lipopolysaccharide-induced mastitis. J. Dairy Sci. 92:922-934.

Wenz, J. R., F. B. Garry, and G. M. Barrington. 2006. Comparison of disease severity scoring systems for dairy cattle with acute coliform mastitis. J. Am. Vet. Med. Assoc. 229:259-262.

Yeiser, E. E., K. E. Leslie, M. L. McGilliard, and C. S. Petersson-Wolfe. 2012. The effects of experimentally induced Escherichia coli mastitis and flunixin meglumine administration on activity measures, feed intake, and milk parameters. J. Dairy Sci. 95:4939-4949. 